\title{
The impact of parental offending on offspring aggression in early childhood: A population-based record linkage study
}

Stacy Tzoumakis ${ }^{1-3}$, Kimberlie Dean ${ }^{2-4}$, Melissa J. Green ${ }^{2,3}$, Catherine Zheng ${ }^{2}$, Maina Kariuki ${ }^{2,3}$, Felicity Harris ${ }^{2,3}$, Vaughan J. Carr ${ }^{2,3,5}$, Kristin R. Laurens ${ }^{2,3}$

\section{Author Affiliations}

1. School of Social Sciences, UNSW Australia

2. School of Psychiatry, UNSW Australia

3. Neuroscience Research Australia, Sydney, Australia

4. Justice Health \& Forensic Mental Health Network, New South Wales, Australia

5. Department of Psychiatry, School of Clinical Sciences, Monash University, Melbourne, Australia

\section{Corresponding Author}

Dr Stacy Tzoumakis, UNSW Australia Kensington Campus, Room G21, Morven Brown Building, Sydney 2052, New South Wales, Australia. Telephone: +61 0283821426 Fax: +61 0283821402 email: s.tzoumakis@unsw.edu.au

\section{Acknowledgments}

This research was conducted by UNSW Australia with financial support from the Australian Institute of Criminology (Research Grant CRG 19/14-15); the Australian Research Council (Linkage Project LP110100150, with the New South Wales (NSW) Ministry of Health, NSW Department of Education, and the NSW Department of Family and Community Services representing the Linkage Project Partners); the National Health and Medical Research Council (NHMRC; Project Grant APP1058652); and Australian Rotary Health (Mental Health Research Grant RG104090). MJG was supported by a NHMRC R.D. Wright Biomedical Career Development Fellowship (APP1061875). This research was conducted using population data owned by the Department of Education, NSW Bureau of Crime Statistics and Research, and NSW Ministry of Health. However the information and views contained in this study do not necessarily, or at all, reflect the views or information held by these Departments. We would like to acknowledge Alessandra Raudino and Enwu Liu for assistance with the preparation of linked data.

Journal: Social Psychiatry and Psychiatric Epidemiology 


\begin{abstract}
Purpose: To examine the impact of parental criminal offending, both paternal and maternal, on offspring aggression at age 5 years, while also considering key risk factors, including parental mental illness, child's sex, and socio-economic disadvantage.
\end{abstract}

Methods: The sample comprised 69,116 children, with linked parental information, from the New South Wales Child Development Study, a population-based multi-agency, multi-generational record linkage study that combines information from a teacher-reported cross-sectional survey of early childhood development at age 5 years (the 2009 Australian Early Development Census; AEDC) with data obtained via administrative records from multiple sources (e.g., health, crime, education, welfare). Hierarchical logistic regression analyses were conducted to determine the effects of maternal and paternal criminal court appearances (frequency, and type of offending), and mental health service contacts, on offspring aggression measured in the AEDC.

Results: Having a parent with a history of offending was significantly associated with high levels of offspring aggression in early childhood. The strength of association was greatest when parents were involved in frequent ( $\geq 6$ offences: adjusted odds ratio [aOR] range $=1.55$ to 1.73 ) and violent (aOR range $=1.49$ to 1.63 ) offending. Both maternal and paternal offending remained significant predictors of offspring aggression after accounting for parental mental illness, and associations were similar in magnitude for maternal and paternal offending histories.

Conclusions: Parental history of severe criminal offending increased the risk of high levels of aggression in offspring during early childhood, highlighting the need for intervention with families during this key developmental period.

Keywords: intergenerational transmission, externalising behaviour, parental mental illness, data linkage, epidemiology 


\section{Introduction}

The transmission of antisocial behaviour and offending from one generation to the next is wellestablished in criminological research; however, much of this research has focused on the impact of fathers' rather than mothers' offending, and offspring outcomes in adolescence and adulthood rather than childhood [1-4]. The emphasis placed on fathers is not surprising given the low rates of offending among women relative to men, particularly for serious and violent offending [5,6]. As a result, few studies have included a large enough number of offending mothers to be able to examine different parameters of offending (e.g., age of onset, duration, frequency, type). The use of multigenerational linked population data in the present study facilitated the investigation of the influence of maternal and paternal offending frequency and type (violent, nonviolent, minor) on high levels of childhood aggression assessed at age 5 years, in the context of a number of important potential risk factors (e.g., child’s sex, socioeconomic disadvantage, and parental mental health status).

Among the studies that have specifically investigated the effects of maternal offending on offspring outcomes, results have been conflicting. Some suggest that fathers plays a more direct role in the transmission of delinquency and offending, whereas the impact of mothers tends to be mediated by other factors (e.g., parenting practices) or is less predictive compared to fathers $[7,4,8]$. Other recent studies have provided contrasting evidence indicating an important effect of maternal offending on offspring outcomes, which in some cases exceeds that of fathers [9-11]. For example, a five generation Dutch study, found that having a mother involved in serious delinquency (e.g., property offences, violent offences, and drugs and weapon offences) conferred as much, if not more, risk for offspring delinquency relative to having a father involved in serious offending [9]. The extent to which the transmission of offending is sex-specific (i.e., mothers to daughters and fathers to sons) remains unclear; while there is often a strong relationship between same-sex intergenerational pairs, the small numbers of mothers and daughters involved in offending make it difficult to conclusively determine the sex-specificity of this transmission $[12,9]$.

In examining the impact of parental offending on offspring, rather than examining the presence of any offending or antisocial behaviour in parents, it is critical to consider multiple parameters of offending 
(e.g., type, age of onset, frequency, and persistence) that distinguish different trajectories and profiles of offenders [13]. One study found that offspring of fathers on a high-rate persistent offending trajectory started offending earlier and were more involved in frequent offending across the lifecourse compared to the offspring of fathers who desisted or were sporadic offenders [3]. While there is a growing body of epidemiological research on the transmission of offending and antisocial behaviour [14,15,10,16], few studies have been sufficiently powered or have the comprehensive criminal history data available to determine the impact of multiple parental offending parameters on offspring outcomes. A large study of approximately 2 million individuals using Swedish register data has more closely examined the transmission of specific types of offending and demonstrated that violent crime is transmitted from parent to offspring to a greater degree than involvement in other crime types (i.e., property and white collar crime) $[17,15]$.

Despite increasing evidence of the early childhood origins of aggression and antisocial behaviour [18], research on the impact of parental offending has not focused on childhood. Research on the transmission of conduct problems (i.e., disruptive, oppositional, externalising behaviours) to offspring in childhood finds evidence of moderate to strong effects [19-22]. Parents with a history of conduct disorder also experience significant disadvantage as adults (e.g., socioeconomic disadvantage, poor romantic relationships), and in turn expose their own children to high levels of adversity and tend to provide suboptimal caregiving environments [21]. Moffitt [23] suggests that these cumulative developmental forces explain the continuity of antisocial behaviour from early childhood in a small group of individuals, namely a life-course persistent subgroup (5-10\% of the population), who engage in pathological levels of criminal and antisocial behaviour [23-25]. The first signs of childhood problems with inhibitory control and emotion regulation typically become apparent at school entry, and aggression is one key outcome of these problems [24]. The small group of children showing the highest levels of aggression at school entry are at high risk of continuing on a high-aggression trajectory that manifests in offending in adolescence [26]. Other predictors of early childhood aggression include male sex, socioeconomic disadvantage, young motherhood, maternal mental illness and substance use problems [27-30]. 


\section{Aim}

The aim of this study was to examine the influence of parental history of offending on offspring aggression at school entry in a large epidemiological sample of over 69,000 Australian children. First, we determined the contribution of both maternal and paternal involvement in offending on offspring aggression in early childhood. Second, we examined the differential impact of both frequency and type of offending on offspring aggression. Third, considering the known association between offending and mental ill health [5,31,32], we established whether the relationship between parental offending and offspring aggression held while accounting for parental history of mental illness.

\section{Method}

\section{Sample and Procedures}

The New South Wales Child Development Study (NSW-CDS; nsw-cds.com.au) is a state-wide prospective, longitudinal, population-based study that uses record linkage of data collections from the most populous State in Australia. This multi-agency, multi-generational data linkage combines information from a teacher-reported cross-sectional survey with administrative records from numerous sources (e.g., health, crime, welfare, and education), and includes both child and parent records [26]. In accordance with strict privacy protection protocols, record linkage was conducted in 2014 by an independent agency, the Centre for Health Record Linkage (CHeReL; www.cherel.org.au) using probabilistic record linkage methods. Child and parent records were linked using matching variables including name, date of birth, residential address and sex. False positive linkages in the NSW-CDS were low, with a rate of 3/1,000 persons (0.3\%) associated with linkage of child data collections, and 5/1,000 persons (0.5\%) for the linkage of parents to their children. The NSW-CDS was defined by the children's entry into the first year of full-time schooling (kindergarten) in 2009 at approximately 5 years of age in the state of New South Wales (NSW). For each child in the state (99.9\% of the eligible NSW children; N=87,026), teachers completed the Australian Early Development Census (AEDC). The AEDC was developed in Canada and is a population measure of children's developmental health at school entry [33]. The psychometric properties of the AEDC have been examined extensively in multiple countries, and have been established using Rasch modelling 
[34-38]. The AEDC's predictive validity has also been demonstrated in relation to middle childhood educational achievement, wellbeing, and peer relations [39,40]. Of the 87,026 children who participated in the AEDC, it was possible to link parental records for 72,245 children whose births were registered in NSW using the NSW Register of Births, Deaths, and Marriages - Birth Registrations [41] $]^{1}$. Valid AEDC data was available for 69,116 of these children (children with special needs were excluded²).

\section{Measures}

Child aggression. Offspring aggression at age 5 years was assessed using the Aggressive Behaviour subdomain of the AEDC. Kindergarten teachers answered seven questions regarding children's aggression (i.e., gets into physical fights; bullies or is mean to others; kicks, bites, hits; takes things; laughs at other children's discomfort; disobedient; and temper tantrums). Children were considered 'developmentally vulnerable' if they scored in the bottom $10 \%$ of the national AEDC population distribution [33]. In the current state sample, $8.3 \%$ of children $(\mathrm{N}=5,510)$ were considered 'developmentally vulnerable' for aggressive behaviour using this criterion; in other words, these children exhibited the highest levels of aggression at school entry based on the national distribution and are likely to include the small group (5-10\%) of life-course persistent antisocial individuals [23,42]. A dichotomous outcome was therefore computed reflecting high levels of child aggression.

Maternal and paternal offending. Parental offending was obtained from the NSW Bureau of Crime Statistics court appearance data (1994-2009). This included information on all criminal court appearances (not limited to convictions) for charges before the Local, District, Supreme, and Children’s Criminal Courts. For each individual charge, categorical indicators for offending frequency and type were created for offspring with offending mothers (8.4\%) and fathers (25.5\%). Parental offending frequency was based on the number of parental charges. Due to the highly skewed distribution of offending frequency, categorical indicators were created as follows: 0 ) no offences; 1 ) one offence; 2) two to five offences; and 3) six or more offences. To compute the offending type

\footnotetext{
${ }^{1}$ In order to conduct the linkage, parents were identified using the children's birth registration records.

${ }^{2}$ Identified as having special needs by their teachers based on medical diagnosis if they required special assistance due to chronic medical, physical, or intellectually disabling conditions.
} 
indicator, mothers and fathers were hierarchically assigned to one of the following groups based on their most serious type of offence: 0 ) none: no offences; 1 ) minor: at least one offence of minor type (e.g., traffic and vehicle offences, public health and safety offences); 2) nonviolent: at least one offence of nonviolent type (e.g., theft, burglary, fraud, drug offences); and 3) violent: at least one violent offence (e.g., homicide, assault, aggravated robbery, sexual assault). Descriptive statistics for these indicators are provided in Table 1.

Maternal and paternal mental illness. Parental mental illness was obtained from the NSW Ministry of Health Mental Health Admitted Patients (public and private hospitals) and Mental Health Ambulatory (public outpatient) records (2001-2009). Dichotomous indicators were computed for offspring whose mothers (11.3\%) and fathers (6.4\%) had contacts with public mental health services for any type of mental illness ${ }^{3}$.

Socio-demographic covariates. To account for known associations with child aggression, the following socio-demographic covariates were included: child sex, child English as a second language (ESL), maternal age at child's birth, and socioeconomic status (SES). Child sex (female/male) and ESL (no/yes) were derived from the AEDC. Maternal age at birth ( $<26$ years $/ \geq 26$ years) was derived from the NSW Register of Births, Deaths, and Marriages - Birth Registrations and the NSW Ministry of Health Perinatal Data Collection. SES was based on the Socio-Economic Index for Areas, which measures the average income and employment status for each residential postcode in Australia [43]. A dichotomous SES indicator was created by recoding the national quintiles into those most disadvantaged (two most disadvantaged quintiles) and least disadvantaged (three remaining quintiles).

\section{Statistical analyses}

Hierarchical logistic regression analyses predicting offspring aggression were conducted in IBM SPSS 23 [44]. Rather than using a software-driven, stepwise approach, we used a sequential approach and added blocks of variables to determine how the addition of key exposure variables (parental

\footnotetext{
${ }^{3}$ Parental mental illness included the following non-mutually exclusive categories: common (e.g., depression, anxiety; 7.7\% of mothers; $2.8 \%$ of fathers), severe (e.g. bipolar, schizophrenia; $1.1 \%$ of mothers; $1.0 \%$ of fathers), substance use (2.6\% of mothers; $2.8 \%$ of fathers), personality ( $0.7 \%$ of mothers; $0.5 \%$ of fathers), other adulthood onset (e.g., mental disorders due to brain damage, dementia; $5.0 \%$ of mothers; $2.8 \%$ of fathers), and other childhood onset disorders (e.g., conduct, attention deficit disorders; $0.2 \%$ of mothers; $0.2 \%$ of fathers).
} 
offending and mental illness) influenced other variables entered in the earlier blocks (Menard, 2010). First, to account for the impact of socio-demographic characteristics on child aggression in the absence of the key exposure variables, we included only the four socio-demographic covariates (Block 1). Second, to determine how much the inclusion of the different parental risk variables changed their respective relationships to offspring aggression, we first added to the model maternal offending (Block 2), followed by paternal offending (Block 3) and, finally, parental mental illness (Block 4). Separate analyses were conducted to examine the impact of parental offending frequency $(0,1,2-5$, and $\geq 6)$ and type (none, minor, nonviolent, and violent $)^{4,5}$. Results were considered statistically significant if the 95\% confidence intervals (CI) did not cross 1.

Several sensitivity analyses were also conducted. To determine any sex differences or sex-specific patterns in the association between parental offending and offspring aggression, all analyses were conducted separately for males and females. On account of the known link between substance use and offending [45], analyses were also completed with indicators of maternal (2.6\%) and paternal (2.8\%) substance use disorders instead of any parental mental illness ${ }^{6}$. To verify whether the results remained consistent when excluding children of non-offending parents, analyses were also conducted restricting the sample to include only those children with an offending mother $(\mathrm{N}=5,711)$ and those with an offending father $(\mathrm{N}=17,493)$. Moreover, to determine the relative importance of parental offending frequency compared to type, two logistic regression analyses were conducted with these parental offender subsets, with frequency and type of parental offending included simultaneously in the models.

\section{Results}

\section{Sample Characteristics}

Descriptive statistics for the total sample $(\mathrm{N}=69,116)$ are presented in Table 1. To determine overall profiles of children whose mothers were involved in offending, these descriptive statistics were also

\footnotetext{
${ }^{4}$ To account for the potential influence of parental absence due to incarceration, analyses were conducted excluding the 1,996 children with a parent who had been incarcerated (296 mothers and 1,818 fathers). Results were unchanged.

${ }^{5}$ Analyses were also conducted excluding children whose parents had a court appearance for non-criminal regulation offences only (e.g., speeding fines, debts; $n=2,639$ ) from the reference group. Results were unchanged.

${ }^{6}$ The prevalence of other mental health problems known to be associated with offending (i.e., antisocial personality and childhood externalizing disorders) was too low to be examined separately.
} 
stratified by maternal offending frequency. A dose-dependent pattern was observed between maternal offending frequency and all of the variables except for child sex and ESL. Specifically, as maternal offending frequency increased, so did the prevalence of young maternal age at child birth, socioeconomic disadvantage, paternal offending frequency, parental mental illness, and offspring aggression. Notably, among children whose mothers had a history of six or more offences, $71.7 \%$ lived in the most disadvantaged areas in the state, $57.4 \%$ had a father with a history of six or more offences, and $64.0 \%$ had a mother with a history of mental illness, compared to $43.2 \%, 4.1 \%$ and 9.2\% of children with non-offending mothers, respectively.

\section{Frequency of Parental Offending and Offspring Aggression}

Unadjusted odds ratios (ORs) were computed using logistic regression for parental offending frequency. For mothers’ offending, the unadjusted ORs were 1.45 (95\% CI=1.28-1.66) for one offence, 2.05 (95\% CI=1.81-2.32) for two to five offences, and 3.15 (95\% CI=2.73-3.64) for six or more offences. For fathers, the unadjusted ORs were 1.38 (95\% CI=1.26-1.51) for one offence, 1.64 (95\% CI=1.51-1.78) for two to five offences, and $2.52(95 \% \mathrm{CI}=2.31-2.75)$ for six or more offences. Hierarchical logistic regression results with parental offending frequency are presented in Table $2^{7}$. All four socio-demographic covariates (child sex, ESL, maternal age at child’s birth, and socioeconomic disadvantage) in the baseline model (Block 1) were significantly associated with offspring aggression. Males were three times more likely than females (OR=3.05; 95\% CI=2.87-3.24) to exhibit high levels of aggression at age 5 years. When maternal offending frequency was added to the model in Block 2, all four socio-demographic covariates remained statistically significant and their magnitudes of association were unchanged. Relative to the reference group with no maternal history of criminal offending, all three categories of maternal offending frequency $(1 ; 2-5 ; \geq 6)$ were associated with high levels of offspring aggression in Block 2. The magnitude of association increased with greater frequency of offending; in particular, maternal history of six or more offences showed the highest magnitude of association with an odds ratio of 2.69 (95\% CI=2.32-3.13) in Block 2. Paternal

\footnotetext{
${ }^{7}$ Model diagnostics indicated the presence of underdispersion in the data. As a result, all analyses were also conducted using quasi-binomial generalized linear models (not presented here). The results did not differ from the logistic models, other than small increases being observed in the standard errors.
} 
offending frequency was added to the model in Block 3, and the ORs for all three paternal offending frequency categories $(1 ; 2-5 ; \geq 6)$ were statistically significant, though slightly lower in magnitude relative to maternal offending frequency, and ranged from 1.30 to 1.74 . With the addition of paternal offending, the ORs for maternal offending decreased in magnitude, and a maternal history of one offence was no longer significantly associated with offspring aggression. Parental mental illness was added to the model in Block 4, which decreased the magnitude of the ORs for maternal and paternal offending across frequency categories, resulting in similar effect sizes for both parents. The magnitudes of the ORs for the child's sex and ESL remained stable, while maternal young age at child's birth and socioeconomic disadvantage decreased compared to the previous blocks in the model. Both maternal and paternal mental illness significantly predicted offspring aggression, with maternal mental illness having a slightly greater magnitude (OR=1.41; 95\% CI=1.30-1.53) compared to paternal mental illness (OR=1.29; 95\% CI=1.16-1.42) $)^{8}$.

\section{Type of Parental Offending and Offspring Aggression}

Unadjusted ORs were computed using logistic regression for maternal and paternal offending type (none, minor, nonviolent, and violent). For mothers, the unadjusted ORs were 1.48 (95\% CI=1.251.74) for minor offending, 1.85 (95\% CI=1.65-2.08) for nonviolent offending, and 2.70 (95\% $\mathrm{CI}=2.38-3.07)$ for violent offending. For fathers, the unadjusted ORs were 1.35 (95\% CI=1.21-1.49) for minor offending, 1.67 (95\% CI=1.53-1.82) for nonviolent offending, and 2.14 (95\% CI=1.98-2.31) for violent offending. Results of the hierarchical logistic regression model with parental offending type are presented in Table 3. Patterns of association for parental offending type were similar to those obtained for offending frequency (Table 2), although the magnitude of the ORs for violent offending was smaller than that of frequent $(\geq 6)$ offending across the blocks of the model. As with maternal history of one offence, maternal history of minor offending was no longer significant after fathers' offending and parental mental illness were added to the model.

\section{Sensitivity Analyses}

\footnotetext{
${ }^{8}$ Analyses with interaction effects between parental offending and mental illness were examined and were non-significant.
} 
Sex-specific analyses. Both sets of analyses (parental offending frequency and type) were completed separately for males and females (see Online Resource Tables S1-S4). The results for male offspring, for both parental frequency and type of offending, were mostly unchanged from those obtained for the full sample, and the magnitudes of the ORs for mothers' and fathers' offending were the same in the analyses restricted to male offspring (Tables S1-S2). For female offspring (Table S3), the OR for mothers involved in 6 or more offences in the final Block was 2.05 (95\% CI=1.56-2.68), which was greater than that for fathers $(\mathrm{OR}=1.46$; $95 \% \mathrm{CI}=1.20-1.78)$ and greater than it was in the full sample $(\mathrm{OR}=1.73 ; 95 \% \mathrm{CI}=1.47-2.4)$. Similarly, the ORs for maternal violent offending were greater than those for fathers in the analyses restricted to female offspring, and paternal involvement in minor offences was no longer significant (Table S4).

Parental substance use disorder. Analyses were repeated with parental substance use disorder as an exposure variable, in place of any parental mental illness (see Online Resource Tables S5-S6). The overall patterns of association observed remained the same, and most of the magnitudes of association remained unchanged; however, the ORs for maternal substance use disorder were greater in both the offending frequency and type models (1.60-1.68) compared to the models that included any maternal mental illness (1.41-1.43).

Subsets of offending parents. Analyses were also conducted restricting the sample to children with offending parents (see Online Resource Tables S7-S11). In the models including only those children with an offending mother ( $\mathrm{N}=5711$; Tables S7-S8), patterns of association remained similar; however, by Block 4, several indicators were no longer statistically significant, including child ESL, socioeconomic disadvantage, paternal offending, and nonviolent maternal offending. No substantive differences were found between analyses conducted with the full sample and those restricted to children with an offending father ( $\mathrm{N}=17,493$; Tables S9-S10). A final set of analyses examined frequency and type of parental offending simultaneously (Table S11). In the analyses restricted to offending mothers, violent and frequent ( $2-5$ and $\geq 6$ offences) maternal offending was significantly associated with offspring aggression, and paternal offending was no longer significant. In the analyses 
restricted to offending fathers, maternal violent and paternal violent and frequent ( $\geq 6$ offences) offending were associated with offspring aggression.

\section{Discussion}

The present study examined the impact of maternal and paternal offending on early childhood aggression in a large epidemiological sample of over 69,000 Australian children. Both mothers' and fathers' involvement in offending contributed to children presenting high levels of aggression at school entry, with similar effect sizes. The most robust influences on high levels of children's aggression were found for child sex (male), followed by parental violent and frequent offending. Parental offending remained an important influence on early childhood aggression even after accounting for parental history of mental illness, or substance use disorders specifically, which also contributed to offspring aggression.

Although three times more fathers (25.5\%) had a history of criminal court appearances than did mothers (8.4\%), both parents influenced their offspring’s aggression. Mothers' offending initially seemed to be more influential on children's aggression relative to fathers', which might be expected since mothers are typically primary caregivers at this age; but, after accounting for additional risk factors, there was little difference in the magnitude of the relationship. Similarly, mothers who were involved in minor and infrequent maternal offending initially appeared to contribute to offspring aggression (unadjusted ORs and Blocks 1-2), but the effect of these mothers with limited criminal involvement was not maintained once fathers' offending was accounted for. This underlines the importance of accounting for different parameters of offending rather than treating offending as a homogeneous behaviour [13]. Moreover, we did not find that the relationship between parental offending and offspring aggression was sex-specific; mothers’ and fathers' offending influenced sons and daughters to similar degrees. We did not, however, examine the mechanisms underlying this transmission, which has been shown to differ by sex [20,12].

Our findings suggest that families where parents were involved in offending tended to experience multiple adversities. Notably, offending mothers were more likely to experience mental illness and 
social disadvantage, and to have a partner who was also involved in offending. This pattern of disadvantage was even more likely for those mothers involved in frequent offending. Other research has similarly shown that antisocial parents are at increased risk of pervasive social impairment impacting the family environments of their children, which in turn can contribute to child behaviour problems including life-course persistent antisocial behaviour [21,24] . Recent studies indicate that both genes and environment contribute substantially to parent-offspring resemblance in antisocial behaviour [46,15], with genes influencing close to $50 \%$ of antisocial behaviour $[47,48]$. The NSWCDS does not have a genetic component, so it was not possible to test this formally in the current study; nonetheless, it is likely that both genetic and environmental influences are transmitted from parents to offspring (passive gene-environment correlations), and contribute to the development of high levels of aggression in early childhood $[16,49]$.

\section{Limitations and strengths}

The administrative data in this large epidemiological study were not collected for research purposes, which may have led to classification errors. An underestimation of parental offending is likely, particularly for older parents in the sample, as court appearance data collection only began in 1994. The use of official data also underestimates offending by failing to capture individuals who do not come to the attention of the criminal justice system; however, research has shown that official and self-reported measures of offending over the life-course are associated [50,51]. Similarly, it is likely that parental mental illness was underestimated as the data collection began in 2001. Moreover, primary care and full private service provider health records were not available, and are likely to reflect additional mental health problems. While over 99\% of mothers in the study are the biological parent, it was not possible to confirm the biological status of fathers. The degree of parental contact with the child was not available; in 2012-2013, 75\% of NSW children lived in intact families with both parents [52]. The study did not include other potentially important control variables such as parenting practices, genetic factors, or individual-level measures of socioeconomic status (e.g., parental education or income), which would be preferable to our geographic measure. These missing variables and potential measurement error in the variables we used increase the possibility of residual 
and unmeasured confounding. The AEDC was developed to measure childhood vulnerability and school readiness rather than to research the development of aggression; as such, the aggressive behaviour subdomain is a broad measure of aggression that includes items reflecting disruptive behaviour. Though such behaviours are strongly related to physical aggression, a disaggregated measure of aggression would have permitted the delineation of effects for different subtypes of aggression [53].

A key strength of the study is the large representative sample that included a substantial number of offending mothers. Moreover, data collection processes were independent (i.e., linkage of parental mental health and crime records with cross-sectional assessment of child aggression). Parental offending and mental health data were collected prospectively, and there was no recall bias or issues with social desirability that occur in smaller longitudinal studies involving self-report. Using population-based administrative data reduces the impact of potential selection and attrition biases, which are a particular issue in the longitudinal research of high-risk groups (e.g., offenders, individuals with mentally illness) [54]. This study focused on early childhood outcomes, but will be followed up with a second record linkage in 2016 for middle childhood outcomes. A cross-sectional self-report assessment of mental health and wellbeing was conducted with approximately one third of the cohort when the children were 11/12 years old, which will enable us to examine the impact of parental offending on offspring aggression longitudinally.

\section{Conclusion}

Both mothers' and fathers' offending impacts offspring aggression during the early childhood period. This supports intervention efforts with 'at-risk' families during this key developmental period. It is well established that early parent/family training programs such as home visitation are effective in the prevention of delinquency and offending [55-57]. This study underlines the potential value of working with both parents at, or prior to, school entry in order to mitigate the development of later antisocial behaviour. While clinicians typically screen for mental ill health among parents of young children presenting for disruptive behaviour problems, screening for parental offending occurs less commonly. It could therefore be useful for psychiatrists and other professionals working with children to screen 
for a wider range of parental risk behaviours. It is also important to systematically intervene and provide support for offending women, especially when they become mothers [58].

\section{Ethical Approval}

Ethical approval was obtained from the NSW Population and Health Services Research Ethics Committee (HREC/11/CIPHS/14), with data custodian approvals granted by the relevant Government Departments, and has therefore been performed in accordance with the ethical standards laid down in the 1964 Declaration of Helsinki and its later amendments that are incorporated into the Australian National Health and Medical Research Council's National Statement on Ethical Conduct in Human Research.

\section{Conflict of Interest}

The authors declare that they have no conflict of interest. 


\section{References}

1. Farrington DP, Barnes GC, Lambert S (1996) The concentration of offending in families. Legal and criminological psychology 1 (1):47-63

2. Loeber R, Stouthamer-Loeber M (1986) Family factors as correlates and predictors of juvenile conduct problems and delinquency. Crime \& Just 7:29

3. van de Rakt M, Nieuwbeerta P, de Graaf ND (2008) Like father, like son: the relationships between conviction trajectories of fathers and their sons and daughters. The British journal of criminology 48

(4):538-556. doi:10.1093/bjc/azn014

4. Farrington DP, Jolliffe D, Loeber R, Stouthamer-Loeber M, Kalb LM (2001) The concentration of offenders in families, and family criminality in the prediction of boys' delinquency. J Adolesc 24 (5):579-596. doi:10.1006/jado.2001.0424

5. Falk Ö, Wallinius M, Lundström S, Frisell T, Anckarsäter H, Kerekes N (2014) The 1\% of the population accountable for $63 \%$ of all violent crime convictions. Soc Psychiatry Psychiatr Epidemiol 49 (4):559-571

6. Junger M, Greene J, Schipper R, Hesper F, Estourgie V (2013) Parental criminality, family violence and intergenerational transmission of crime within a birth cohort. European journal on criminal policy and research 19 (2):117-133. doi:10.1007/s10610-012-9193-z

7. Thornberry TP, Freeman-Gallant A, Lizotte AJ, Krohn MD, Smith CA (2003) Linked lives: The intergenerational transmission of antisocial behavior. J Abnorm Child Psychol 31 (2):171-184 8. Farrington DP, Coid JW, Murray J (2009) Family factors in the intergenerational transmission of offending. Criminal behaviour and mental health : CBMH 19 (2):109-124. doi:10.1002/cbm.717 9. Bijleveld CCJH, Wijkman M (2009) Intergenerational continuity in convictions: A five-generation study. Criminal behaviour and mental health : CBMH 19 (2):142-155. doi:10.1002/cbm.714 10. Vaughn MG, Salas-Wright CP, DeLisi M, Qian Z (2015) The antisocial family tree: family histories of behavior problems in antisocial personality in the United States. Soc Psychiatry Psychiatr Epidemiol 50 (5):821-831. doi:10.1007/s00127-014-0987-9

11. Laurens KR, Tzoumakis S, Kariuki M, Green MJ, Hamde M, Harris F, Carr VJ, Dean K (2016) Pervasive influence of maternal and paternal criminal offending on early childhood development: A population data linkage study. Psychol Med Advance online publication doi:

https://doi.org/10.1017/S0033291716003007

12. Auty KM, Farrington DP, Coid JW (2015) The Intergenerational Transmission of Criminal Offending: Exploring Gender-Specific Mechanisms. British Journal of Criminology:azv115 13. Piquero AR (2008) Taking stock of developmental trajectories of criminal activity over the life course. In: The long view of crime: A synthesis of longitudinal research. Springer, pp 23-78 14. Frisell T, Lichtenstein P, Långström N (2011) Violent crime runs in families: a total population study of 12.5 million individuals. Psychological medicine 41 (01):97-105

15. Kendler KS, Ohlsson H, Morris NA, Sundquist J, Sundquist K (2015) A Swedish populationbased study of the mechanisms of parent-offspring transmission of criminal behavior. Psychol Med 45 (5):1093-1102. doi:10.1017/S0033291714002268

16. Beaver KM (2013) The familial concentration and transmission of crime. Criminal justice and behavior 40 (2):139-155. doi:10.1177/0093854812449405

17. Frisell T, Lichtenstein P, Langstrom N (2011) Violent crime runs in families: a total population study of 12.5 million individuals. Psychol Med 41 (1):97-105. doi:10.1017/S0033291710000462 18. Tremblay RE (2015) Antisocial Behavior Before the Age-Crime Curve: Can Developmental Criminology Continue to Ignore Developmental Origins? In: Morizot J, Kazemian L (eds) The Development of Criminal and Antisocial Behavior. Springer, Switzerland, pp 39-49 19. Raudino A, Fergusson DM, Woodward LJ, Horwood LJ (2013) The intergenerational transmission of conduct problems. Soc Psychiatry Psychiatr Epidemiol 48 (3):465-476. doi:10.1007/s00127-012-0547-0

20. D'Onofrio BM, Slutske WS, Turkheimer E, Emery RE, Harden KP, Heath AC, Madden PA, Martin NG (2007) Intergenerational transmission of childhood conduct problems: A children of twins study. Arch Gen Psychiatry 64 (7):820-829. doi:10.1001/archpsyc.64.7.820

21. Jaffee SR, Belsky J, Harrington H, Caspi A, Moffitt TE (2006) When parents have a history of conduct disorder: How is the caregiving environment affected? J Abnorm Psychol 115 (2):309-319. doi:10.1037/0021-843X.115.2.309 
22. Murray J, Farrington DP (2010) Risk factors for conduct disorder and delinquency: key findings from longitudinal studies. Canadian Journal of Psychiatry 55 (10):633

23. Moffitt TE (1993) Adolescence-limited and life-course-persistent antisocial behavior: a developmental taxonomy. Psychol Rev 100 (4):674

24. DeLisi M, Vaughn MG (2014) Foundation for a temperament-based theory of antisocial behavior and criminal justice system involvement. Journal of Criminal Justice 42 (1):10-25

25. DeLisi M, Piquero AR (2011) New frontiers in criminal careers research, 2000-2011: A state-ofthe-art review. Journal of Criminal Justice 39 (4):289-301

26. Broidy LM, Nagin DS, Tremblay RE, Bates JE, Brame B, Dodge KA, Fergusson D, Horwood JL, Loeber R, Laird R (2003) Developmental trajectories of childhood disruptive behaviors and adolescent delinquency: a six-site, cross-national study. Dev Psychol 39 (2):222

27. Tremblay RE, Nagin DS, Seguin JR, Zoccolillo M, Zelazo PD, Boivin M, Perusse D, Japel C (2004) Physical aggression during early childhood: Trajectories and predictors. Pediatrics 114 (1):e43-50

28. Tzoumakis S, Lussier P, Corrado RR (2014) The persistence of early childhood physical aggression: Examining maternal delinquency and offending, mental health, and cultural differences. Journal of Criminal Justice 42 (5):408-420

29. NICHD Early Child Care Research Network (2004) Trajectories of physical aggression from toddlerhood to middle childhood: predictors, correlates, and outcomes. Monogr Soc Res Child Dev 69 (4):vii, 1

30. Mazza JRS, Boivin M, Tremblay RE, Michel G, Salla J, Lambert J, Zunzunegui MV, Côté SM (2016) Poverty and behavior problems trajectories from 1.5 to 8 years of age: Is the gap widening between poor and non-poor children? Soc Psychiatry Psychiatr Epidemiol:1-10

31. Odgers CL, Moffitt TE, Broadbent JM, Dickson N, Hancox RJ, Harrington H, Poulton R, Sears MR, Thomson WM, Caspi A (2008) Female and male antisocial trajectories: From childhood origins to adult outcomes. Dev Psychopathol 20 (2):673-716. doi:10.1017/S0954579408000333

32. Vaughn MG, Salas-Wright CP, DeLisi M, Maynard BR, Boutwell B (2015) Prevalence and correlates of psychiatric disorders among former juvenile detainees in the United States. Compr Psychiatry 59:107-116

33. Brinkman S, Gregory T, Goldfeld S, Lynch J, Hardy M (2014) Data Resource Profile: The Australian Early Development Index (AEDI). Int J Epidemiol 43 (4):1089-1096

34. Brinkman SA, Silburn S, Lawrence D, Goldfeld S, Sayers M, Oberklaid F (2007) Investigating the Validity of the Australian Early Development Index. Early Education and Development 18 (3):427451. doi:10.1080/10409280701610812

35. Janus M, Brinkman SA, Duku EK (2011) Validity and psychometric properties of the early development instrument in Canada, Australia, United States, and Jamaica. Social Indicators Research 103 (2):283-297

36. Janus M, Offord DR (2007) Development and psychometric properties of the Early Development Instrument (EDI): A measure of children's school readiness. Canadian Journal of Behavioural Science/Revue canadienne des sciences du comportement 39 (1):1

37. Andrich D, Styles I (2004) Final report on the psychometric analysis of the Early Development Instrument (EDI) using the Rasch Model: A technical paper commissioned for the development of the Australian Early Development Instrument (AEDI).

38. Hagquist C, Hellström L (2014) The psychometric properties of the Early Development Instrument: a Rasch analysis based on Swedish pilot data. Social indicators research 117 (1):301-317 39. Brinkman SA, Gregory T, Harris J, Hart B, Blackmore S, Janus M (2013) Associations between the early development instrument at age 5, and reading and numeracy skills at ages 8, 10 and 12: A prospective linked data study. Child Indicators Research 6 (4):695-708. doi:10.1007/s12187-0139189-3

40. Guhn M, Gadermann AM, Almas A, Schonert-Reichl KA, Hertzman C (2016) Associations of teacher-rated social, emotional, and cognitive development in kindergarten to self-reported wellbeing, peer relations, and academic test scores in middle childhood. Early Childhood Research Quarterly 35:76-84

41. Carr VJ, Harris F, Raudino A, Luo L, Kariuki M, Liu E, Tzoumakis S, Smith M, Holbrook A, Bore M, Brinkman S, Lenroot R, Dix K, Dean K, Laurens KR, Green MJ (2016) New South Wales 
Child Development Study (NSW-CDS): an Australian multiagency, multigenerational, longitudinal record linkage study. BMJ Open 6 (2):e009023. doi:10.1136/bmjopen-2015-009023

42. DeLisi M (2005) Career criminals in society. Sage, Thousand Oaks, CA

43. Australian Government (2011) Census of Population and Housing: Socio-Economic Indexes for 481 Areas (SEIFA).

44. IBM (2015) IBM SPSS Statistics for Windows, Version 22.0. IBM Corp., Armonk, NY

45. DeLisi M, Vaughn MG, Salas-Wright CP, Jennings WG (2015) Drugged and dangerous prevalence and variants of substance use comorbidity among seriously violent offenders in the United States. Journal of Drug Issues 45 (3):232-248

46. Bornovalova MA, Cummings JR, Hunt E, Blazei R, Malone S, Iacono WG (2014) Understanding the relative contributions of direct environmental effects and passive genotype-environment correlations in the association between familial risk factors and child disruptive behavior disorders. Psychol Med 44 (4):831-844

47. Moffitt TE (2005) The new look of behavioral genetics in developmental psychopathology: geneenvironment interplay in antisocial behaviors. Psychol Bull 131 (4):533

48. Blazei RW, Iacono WG, Krueger RF (2006) Intergenerational transmission of antisocial behavior: How do kids become antisocial adults? Applied and Preventive Psychology 11 (4):230-253. doi:10.1016/j.appsy.2006.07.001

49. Vitaro F, Brendgen M (2016) Introduction to the special section "Environmental effects on development: Concordance and discrepancies between genetically-controlled and non geneticallycontrolled studies”. International Journal of Behavioral Development 40 (3):193-195

50. Payne JL, Piquero AR (2016) The concordance of self-reported and officially recorded lifetime offending histories: Results from a sample of Australian prisoners. Journal of Criminal Justice 46:184-195

51. Maxfield MG, Weiler BL, Widom CS (2000) Comparing self-reports and official records of arrests. Journal of Quantitative Criminology 16 (1):87-110

52. Australian Bureau of Statistics (2015) Release 4442.0 - Family Characteristics and Transitions, Australia, 2012-13 (Data Cube: Households, Families and Persons, Selected characteristics by State). Australian Bureau of Statistics. Accessed 30 June 2016

53. Tremblay RE (2010) Developmental origins of disruptive behaviour problems: the 'original sin'hypothesis, epigenetics and their consequences for prevention. Journal of Child Psychology and Psychiatry 51 (4):341-367

54. Magnusson D, Bergman LR (1990) Data quality in longitudinal research. Cambridge University Press, Cambridge

55. Piquero AR, Farrington DP, Welsh BC, Tremblay R, Jennings WG (2009) Effects of early family/parent training programs on antisocial behavior and delinquency. Journal of Experimental Criminology 5 (2):83-120

56. Piquero AR, Jennings WG, Diamond B, Farrington DP, Tremblay RE, Welsh BC, Gonzalez JMR (2016) A meta-analysis update on the effects of early family/parent training programs on antisocial behavior and delinquency. Journal of Experimental Criminology:1-20

57. Olds DL, Sadler L, Kitzman H (2007) Programs for parents of infants and toddlers: recent evidence from randomized trials. Journal of child psychology and psychiatry 48 (3-4):355-391 58. Tremblay RE (2015) Developmental origins of chronic physical aggression: An international perspective on using singletons, twins and epigenetics. European Journal of Criminology 12 (5):551561 


\begin{tabular}{|c|c|c|c|c|c|}
\hline & \multirow[b]{2}{*}{$\begin{array}{c}\text { Total sample } \\
(\mathrm{N}=69,116)\end{array}$} & \multicolumn{4}{|c|}{ Maternal offending frequency } \\
\hline & & $\begin{array}{c}0 \text { offences } \\
(\mathrm{N}=63,341)\end{array}$ & $\begin{array}{c}1 \text { offence } \\
(\mathrm{N}=2,459)\end{array}$ & $\begin{array}{c}2-5 \text { offences } \\
(\mathrm{N}=2,134)\end{array}$ & $\begin{array}{c}\geq 6 \text { offences } \\
(\mathrm{N}=1,182)\end{array}$ \\
\hline & $\%(\mathrm{~N})$ & $\%(\mathrm{~N})$ & $\%(\mathrm{~N})$ & $\%(\mathrm{~N})$ & $\%(\mathrm{~N})$ \\
\hline \multicolumn{6}{|l|}{ Child aggression at age 5 years } \\
\hline Not developmentally vulnerable & $91.7(62,935)$ & $92.2(58,047)$ & $89.1(2175)$ & $85.2(1,793)$ & $79.0(920)$ \\
\hline Developmentally vulnerable & $8.3(5,729)$ & $7.8(4,906)$ & $10.9(267)$ & $14.8(311)$ & $21.0(245)$ \\
\hline \multicolumn{6}{|l|}{ Child sex } \\
\hline Female & $49.5(34,185)$ & $49.4(31,305)$ & $49.0(1206)$ & $50.1(1,069)$ & $51.2(605)$ \\
\hline Male & $50.5(34,931)$ & $50.6(32,036)$ & $51.0(1253)$ & $49.9(1,065)$ & $48.8(577)$ \\
\hline \multicolumn{6}{|l|}{ Child English as a second language } \\
\hline No & $84.1(58,123)$ & $83.6(52,962)$ & $86.7(2132)$ & $90.1(1,923)$ & $93.6(1,106)$ \\
\hline Yes & $15.9(10,993)$ & $16.4(10,379)$ & $13.3(327)$ & $9.9(211)$ & $6.4(76)$ \\
\hline \multicolumn{6}{|l|}{ Maternal age at child's birth } \\
\hline$<26$ years & $21.9(15,147)$ & $19.8(12,514)$ & $40.1(985)$ & $49.3(1,051)$ & $50.5(597)$ \\
\hline$\geq 26$ years & $78.1(53,969)$ & $80.2(50,827)$ & $59.9(1474)$ & $50.7(1,083)$ & $49.5(585)$ \\
\hline \multicolumn{6}{|l|}{ Socioeconomic status } \\
\hline Least Disadvantaged & $55.0(38,030)$ & $56.8(35,995)$ & $40.7(1000)$ & $32.8(700)$ & $28.3(335)$ \\
\hline Most Disadvantaged & $45.0(31,076)$ & $43.2(27,336)$ & $59.3(1459)$ & $67.2(1,434)$ & 71.7 (847) \\
\hline \multicolumn{6}{|l|}{ Maternal offending type } \\
\hline None & $91.7(63,341)$ & $100.0(63,341)$ & $0.0(0)$ & $0.0(0)$ & $0.0(0)$ \\
\hline Minor & $2.1(1,450)$ & $0.0(0)$ & $40.1(984)$ & $20.1(428)$ & $3.2(38)$ \\
\hline Nonviolent & $3.8(2,593)$ & $0.0(0)$ & $46.3(1,134)$ & $48.9(1,044)$ & $35.1(415)$ \\
\hline Violent & $2.5(1,724)$ & $0.0(0)$ & $13.6(333)$ & $31.0(662)$ & 61.7 (729) \\
\hline \multicolumn{6}{|l|}{ Paternal offending type } \\
\hline None & $74.5(51,485)$ & $77.9(49,308)$ & $46.0(1,130)$ & 34.4 (733) & $26.6(314)$ \\
\hline Minor & $6.7(4,617)$ & $6.6(4,173)$ & $9.4(232)$ & 7.9 (168) & $3.7(44)$ \\
\hline Nonviolent & $8.9(6,153)$ & $8.3(5,235)$ & 16.2 (399) & $16.2(345)$ & $14.7(174)$ \\
\hline Violent & $9.9(6,853)$ & $7.3(4,618)$ & $28.4(698)$ & $41.6(887)$ & $55.0(650)$ \\
\hline \multicolumn{6}{|l|}{ Paternal offending frequency } \\
\hline 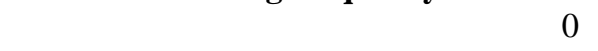 & $74.5(51,485)$ & $77.8(49,308)$ & $46.0(1,130)$ & $34.3(733)$ & $26.6(314)$ \\
\hline 1 & $9.2(6,335)$ & $9.1(5,795)$ & $12.1(297)$ & $9.0(191)$ & $4.4(52)$ \\
\hline $2-5$ & $9.7(6,712)$ & $8.9(5,622)$ & $21.1(520)$ & $20.2(432)$ & $11.7(138)$ \\
\hline$\geq 6$ & $6.6(4,584)$ & $4.1(2,616)$ & $20.8(512)$ & 36.5 (778) & $57.4(678)$ \\
\hline \multicolumn{6}{|l|}{ Maternal mental illness } \\
\hline 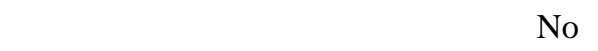 & $88.7(61,292)$ & $90.8(57,544)$ & $78.3(1,926)$ & $65.4(1396)$ & $36.0(426)$ \\
\hline Yes & $11.3(7,824)$ & $9.2(5,797)$ & $21.7(533)$ & $34.6(738)$ & $64.0(756)$ \\
\hline \multicolumn{6}{|l|}{ Paternal mental illness } \\
\hline 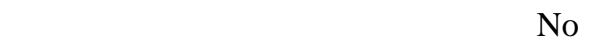 & $93.6(64,670)$ & $94.9(60,081)$ & $85.7(2,108)$ & 78.8 (1681) & $67.7(800)$ \\
\hline Yes & $6.4(4,446)$ & $5.1(3,260)$ & $14.3(351)$ & 21.2 (453) & $32.3(382)$ \\
\hline
\end{tabular}


Table 2: Associations between parental offending frequency and offspring aggression at age 5 years

\begin{tabular}{|c|c|c|c|c|}
\hline & $\begin{array}{c}\text { Block 1 } \\
\text { OR (95\% CI) }\end{array}$ & $\begin{array}{c}\text { Block } 2 \\
\text { OR (95\% CI) }\end{array}$ & $\begin{array}{c}\text { Block 3 } \\
\text { OR (95\% CI) }\end{array}$ & $\begin{array}{c}\text { Block } 4 \\
\text { OR }(95 \% \mathrm{CI})\end{array}$ \\
\hline Female & 1 & 1 & 1 & 1 \\
\hline \multicolumn{5}{|l|}{ Child English as a second language } \\
\hline 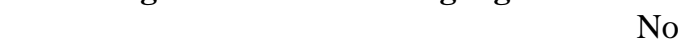 & 1 & 1 & 1 & 1 \\
\hline Yes & $0.81(0.75-0.88)$ & $0.85(0.78-0.92)$ & $0.87(0.81-0.95)$ & $0.90(0.83-0.97)$ \\
\hline$<26$ years & $1.67(1.57-1.77)$ & $1.56(1.46-1.66)$ & $1.44(1.35-1.53)$ & $1.42(1.33-1.51)$ \\
\hline \multicolumn{5}{|l|}{ Socioeconomic status } \\
\hline Least Disadvantaged & 1 & 1 & 1 & 1 \\
\hline Most Disadvantaged & 1.31(1.24-1.39) & $1.26(1.19-1.33)$ & $1.21(1.14-1.28)$ & $1.20(1.13-1.27)$ \\
\hline \multicolumn{5}{|l|}{ Maternal offending frequency } \\
\hline 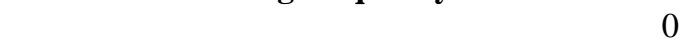 & & 1 & 1 & 1 \\
\hline \multicolumn{5}{|l|}{ Paternal offending frequency } \\
\hline 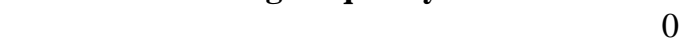 & & & 1 & 1 \\
\hline 1 & & & $1.30(1.19-1.43)$ & $1.28(1.16-1.40)$ \\
\hline $2-5$ & & & $1.42(1.30-1.55)$ & $1.37(1.25-1.49)$ \\
\hline$\geq 6$ & & & $1.74(1.57-1.92)$ & $1.55(1.39-1.73)$ \\
\hline \multicolumn{5}{|l|}{ Maternal mental illness } \\
\hline No & & & & 1 \\
\hline Yes & & & & $1.41(1.30-1.53)$ \\
\hline \multicolumn{5}{|l|}{ Paternal mental illness } \\
\hline 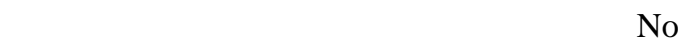 & & & & 1 \\
\hline Yes & & & & $1.29(1.16-1.42)$ \\
\hline
\end{tabular}

Note: $\mathrm{N}=68,655$; $\mathrm{OR}=$ odds ratio; $\mathrm{CI}=$ confidence interval. 


\begin{tabular}{|c|c|c|c|c|}
\hline & $\begin{array}{c}\text { Block 1 } \\
\text { OR }(95 \% \text { CI })\end{array}$ & $\begin{array}{c}\text { Block 2 } \\
\text { OR }(95 \% \text { CI })\end{array}$ & $\begin{array}{c}\text { Block 3 } \\
\text { OR }(95 \% \mathrm{CI})\end{array}$ & $\begin{array}{c}\text { Block } 4 \\
\text { OR }(95 \% \mathrm{CI}) \\
\end{array}$ \\
\hline \multicolumn{5}{|l|}{ Child sex } \\
\hline Female & 1 & 1 & 1 & 1 \\
\hline Male & $3.05(2.87-3.24)$ & $3.07(2.89-3.26)$ & $3.08(2.90-3.27)$ & $3.09(2.90-3.28)$ \\
\hline \multicolumn{5}{|l|}{ Child English as a second language } \\
\hline$x_{0}$ & 1 & 1 & 1 & 1 \\
\hline Yes & $0.81(0.75-0.88)$ & $0.85(0.78-0.92)$ & $0.87(0.80-0.94)$ & $0.90(0.83-0.97)$ \\
\hline \multicolumn{5}{|l|}{ Maternal age at child's birth } \\
\hline$\geq 26$ years & 1 & 1 & 1 & 1 \\
\hline$<26$ years & $1.67(1.57-1.77)$ & $1.55(1.46-1.66)$ & $1.44(1.35-1.54)$ & $1.42(1.33-1.51)$ \\
\hline \multicolumn{5}{|l|}{ Socioeconomic status } \\
\hline Least Disadvantaged & 1 & 1 & 1 & 1 \\
\hline Most Disadvantaged & $1.31(1.24-1.39)$ & $1.26(1.19-1.34)$ & $1.22(1.15-1.29)$ & $1.20(1.13-1.27)$ \\
\hline \multicolumn{5}{|l|}{ Maternal offending type } \\
\hline None & & 1 & 1 & 1 \\
\hline Minor & & $1.32(1.11-1.56)$ & $1.15(0.96-1.36)$ & $1.10(0.93-1.31)$ \\
\hline Nonviolent & & $1.58(1.40-1.78)$ & $1.36(1.20-1.54)$ & $1.23(1.08-1.39)$ \\
\hline Violent & & $2.29(2.01-2.61)$ & $1.90(1.66-2.18)$ & $1.63(1.42-1.88)$ \\
\hline \multicolumn{5}{|l|}{ Paternal offending type } \\
\hline None & & & 1 & 1 \\
\hline Minor & & & $1.25(1.12-1.39)$ & $1.23(1.11-1.37)$ \\
\hline Nonviolent & & & $1.44(1.31-1.57)$ & $1.38(1.26-1.51)$ \\
\hline Violent & & & $1.63(1.50-1.78)$ & $1.49(1.36-1.63)$ \\
\hline \multicolumn{5}{|l|}{ Maternal mental illness } \\
\hline No & & & & 1 \\
\hline Yes & & & & $1.43(1.32-1.54)$ \\
\hline \multicolumn{5}{|l|}{ Paternal mental illness } \\
\hline 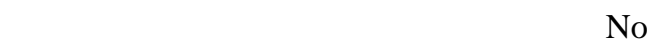 & & & & 1 \\
\hline Yes & & & & $1.32(1.19-1.45)$ \\
\hline
\end{tabular}

Note: $\mathrm{N}=68,639$; $\mathrm{OR}=$ odds ratio; $\mathrm{CI}=$ confidence interval. 